\title{
Impact of Pharmacists in a Community-Based Home Care Service: A Pilot Program
}

\author{
Ashley N Walus and Donna M M Woloschuk
}

\begin{abstract}
Background: Historically, pharmacists have not been included on home care teams, despite the fact that home care patients frequently experience medication errors. Literature describing Canadian models of pharmacy practice in home care settings is limited. The optimal service delivery model and distribution of clinical activities for home care pharmacists remain unclear.
\end{abstract}

Objectives: The primary objective was to describe the impact of a pharmacist based at a community home care office and providing home visits, group education, and telephone consultations. The secondary objective was to determine the utility of acute care clinical pharmacy key performance indicators (cpKPIs) in guiding home care pharmacy services, in the absence of validated cpKPIs for ambulatory care.

Methods: The Winnipeg Regional Health Authority hired a pharmacist to develop and implement the pilot program from May 2015 to July 2016. A referral form, consisting of consultation criteria used in primary care practices, was developed. The pharmacist also reviewed all patient intakes and all patients waiting in acute care facilities for initiation of home care services, with the goal of addressing issues before admission to the Home Care Program. A password-protected database was built for data collection and analysis, and the data are presented in aggregate.

Results: A total of 197 referrals, involving 184 patients, were received during the pilot program; of these, 62 were excluded from analysis. The majority of referrals $(95[70.4 \%])$ were for targeted medication reviews, and 271 drug therapy problems were identified. Acceptance rates for the pharmacist's recommendations were $90.2 \%$ ( 74 of 82 recommendations) among home care staff and $47.0 \%$ (55 of 117 recommendations) among prescribers and patients. On average, $1.5 \mathrm{cpKPIs}$ were identified for each referral.

Conclusions: The pilot program demonstrated a need for enhanced access to clinical pharmacy services for home care patients, although the best model of service provision remains unclear. More research is warranted to determine the optimal pharmacy service for home care patients and the most appropriate cpKPIs to measure its effects.

Keywords: home care, ambulatory care, clinical pharmacy key performance indicators (cpKPIs)

\section{RÉSUMÉ}

Contexte : Historiquement, les équipes de soins à domicile ne comptaient pas de pharmaciens, et ce, malgré le fait que des erreurs de médicaments sont fréquentes chez les patients bénéficiant de ces soins. Il y a peu de documentation sur les modèles canadiens de pratique de la pharmacie en soins à domicile. Le choix optimal du modèle de prestation de services et de distribution des activités cliniques pour les pharmaciens en soins à domicile reste méconnu.

Objectifs : L'objectif principal était de décrire l'effet d'un pharmacien travaillant dans un centre communautaire de soins à domicile, faisant des visites à domicile, de l'éducation de groupe et des consultations téléphoniques. L’objectif secondaire était de déterminer si les indicateurs clés de rendement relatifs à la pharmacie clinique (ICRpc, c.à-d. clinical pharmacy key performance indicators [cpKPI] en anglais) en soins de courte durée étaient utiles pour orienter les services de pharmacie en soins à domicile en l'absence d'ICRpc validés en soins ambulatoires.

Méthodes : La Winnipeg Regional Health Authority a embauché un pharmacien pour élaborer et mettre en œuvre un programme pilote se déroulant de mai 2015 à juillet 2016. Un formulaire de demande de consultation, constitué de critères de consultation employés dans les établissements de soins primaires, a été mis au point. Le pharmacien a aussi évalué toutes les admissions de patients au centre communautaire de soins à domicile et tous les patients attendant en établissements de soins de courte durée que débutent leurs soins à domicile dans le but de s'attaquer aux problèmes avant leur admission au programme. Une base de données protégée par un mot de passe a été créée pour y recueillir les données et les analyser. Les données étaient présentées de façon agrégée.

Résultats : Au total, 197 demandes de consultation visant 184 patients ont été reçues pendant le programme pilote; parmi celles-ci, 62 ont été exclues de l'analyse. La plupart (95 [70,4\%]) étaient des demandes d'évaluation ciblée de médicaments et 271 problèmes pharmacothérapeutiques ont été repérés. Les taux d'acceptation des recommandations du pharmacien étaient de $90 \%$ (74 des 82 recommandations) chez le personnel de soins à domicile et de $47 \%$ (55 des 117 recommandations) chez les prescripteurs et les patients. En moyenne, 1,5 ICRpc a été identifié pour chaque demande de consultation.

Conclusions : Le projet pilote a montré la nécessité d'améliorer l'accès aux services de pharmacie clinique pour les patients en soins à domicile, mais l'on ignore toujours quel serait le meilleur modèle de prestation de services. De plus amples recherches seraient donc justifiées afin de déterminer quels services de pharmacie sont optimaux pour les patients bénéficiant de soins à domicile et quels ICRpc sont les plus adéquats pour en mesurer les effets.

Mots clés : soins à domicile, soins ambulatoires, indicateurs clés de rendement relatifs à la pharmacie clinique (ICRpc) 


\section{INTRODUCTION}

W 1th ever-increasing patient volumes in acute care, health authorities are looking for alternative ways to provide health care to the aging Canadian population. Home care can be a means of providing safe, effective health care to meet patient and family needs. ${ }^{1}$ Health Canada defines home care as "services [that] help people to receive care at home, rather than in a hospital or long-term care facility, and to live as independently as possible in the community."

Historically, pharmacists have not been included in traditional (co-located) home care teams, despite the fact that medication errors are one of the most frequently occurring events for home care patients. ${ }^{3,4}$ Medication contributes to $21.5 \%$ of adverse events among Canadian home care patients, and medication-related incidents increase the risk of death among these patients by $29 \%{ }^{3}$ In addition, polypharmacy increases home care patients' risk of experiencing an adverse event by $20 \%$. 3,5

Literature describing Canadian models of pharmacy practice in home care settings is limited. Available studies have shown decreased health care utilization, decreased costs to the health system, and improved medication management with pharmacy involvement in home care. ${ }^{6,7}$ Beneficial patient outcomes of pharmacy practice in home care settings, such as decreased hospital admissions, decreased emergency department visits, improved quality of life, improved compliance, and decreased adverse events, have been described in other developed countries. ${ }^{8,9}$ In acute care settings, pharmacists improve a variety of patient outcomes, including mortality, length of stay, hospital readmissions, emergency department visits, medication errors, adverse drug events, and compliance. ${ }^{10-12}$ The literature also supports the positive effects of pharmacy practice in ambulatory care settings, such as decreased benzodiazepine use, improved anxiety scores, improved cardiac outcomes, and improved compliance. ${ }^{13-15}$

The optimal service delivery model for pharmacists working in home care remains unclear; both home visits and telephonebased practices have been described. ${ }^{6-8,16,17}$ Home care clinicians in the Winnipeg Regional Health Authority (WRHA) currently rely on community pharmacists for assistance with medicationrelated issues. Community pharmacists are limited in terms of the patient information that is available to them, which can affect their ability to make prescription changes. Many patients are followed by private practice prescribers working outside the purview of the health authority, which adds another layer of complexity in coordinating timely access to health services.

Most home care pharmacy programs described in the literature provide several services, including comprehensive or targeted medication reviews; education for patients, families, and staff; and provision of drug information. ${ }^{6-8,16,17}$ The ideal distribution of clinical activities for home care pharmacists remains unknown. Clinical pharmacy key performance indicators (cpKPIs) have been developed to guide pharmacist duties in acute care, and these measures have been shown to improve patient outcomes. ${ }^{18}$ Similar measures for ambulatory care have not yet been published. The applicability of acute care cpKPIs in an ambulatory care environment has not been studied.

Given the focus on home care as an option for health system renewal, it is important to evaluate the provision of home care services to ensure that care is optimized and meets patient needs. The primary objective of this study was to pilot-test and describe the impact of a pharmacist based at a community home care office, providing pharmacy services such as home visits, group education, and telephone consultations. The secondary objective was to determine the utility of acute care cpKPIs in guiding home care pharmacy services, in the absence of validated ambulatory care cpKPIs.

\section{METHODS}

\section{Home Care Program of the WRHA}

The WRHA Home Care Program is divided into community areas with known population and health needs. Stakeholder consultation identified the Downtown Community Area as having the willingness, space, patient demographic profile, and case load to support the pilot program. This $16.3-\mathrm{km}^{2}$ area is home to people from the entire socioeconomic spectrum and serves approximately 1300 people at any given time. ${ }^{19}$

The Home Care Program team consists of 2 main divisions: community services and nursing services. Community services are coordinated by case coordinators, scheduled by resource coordinators, and delivered by direct service staff. Case coordinators are health professionals from a variety of disciplines, including social workers, nurses, occupational therapists, and dieticians. Resource coordinators are not required to have a health professional background; direct service staff may or may not have a health certificate. Nursing services are coordinated by nursing resource coordinators, scheduled by administrative assistants, and provided by visiting nurses. Nursing resource coordinators are registered nurses, and visiting nurses can be either registered nurses or licensed practical nurses. Patients may receive service from either or both of the community and nursing teams. Case coordinators and nursing resource coordinators are based in the community area office, whereas direct service staff and visiting nurses spend most of their day in the community and are in the office only infrequently.

Medication assistance and medication administration services are split between the 2 teams. Medication assistance refers to services that aid patients who lack independence in taking their medication as prescribed ${ }^{20}$; these services are delivered by direct service staff. Medication administration refers to the provision of medications by a nurse. ${ }^{21}$ Patients can receive medication services up to 4 times per day. 


\section{Pharmacy Pilot Program}

A pharmacist (A.N.W.) was hired (0.9 full-time equivalent) to develop and implement the pilot program from May 2015 to July 2016. The pharmacist was based in the Downtown Community Area office and was available from Monday to Friday during the day shift. During the first half of the pilot program, the pharmacist's desk was situated among those of the case coordinators. Midway through the pilot, the office space was reconfigured, and the pharmacist was moved to the nursing team's work area. Pilot implementation followed the guidelines for integration into primary care teams described by Jorgenson and others. ${ }^{22}$ This pilot program was approved by the University of Manitoba Health Research Ethics Board and was conducted in accordance with the Helsinki Declaration.

A referral form was developed using consultation criteria that are typically used in primary care practices (available from the corresponding author upon request). Referrals were accepted via the form or via e-mail, phone call, or hallway conversation. Patients were excluded from the pharmacist's workload if they did not live within the catchment area of the pilot program. Case-finding using the electronic medical record was planned; however, this method proved impossible, as the system did not enable data-gathering queries or generation of patient case lists. Consent for pharmacist involvement was implied by the patient's acceptance of services from the Home Care Program, because pharmacy services were considered to be one of the care options available to all patients in this community area for the duration of the pilot program; the Health Research Ethics Board waived the need for a separate consent process for patients whose cases were reviewed by the pharmacist. Patients could withdraw their consent to receive pharmaceutical care at any time before or during their interaction with the pharmacist. The pharmacist contacted patients as required to set up phone or in-person meetings; the patient chose the type of meeting. A pharmaceutical care plan was developed and recommendations were shared, in compliance with provincial privacy legislation, with the patient, family, home care staff, and prescribers. Communication included documentation in the electronic or paper chart, phone calls, and messages sent by facsimile. In addition to referrals, the pharmacist reviewed all patient intakes and all patients who were waiting in acute care facilities for initiation of home care service ("hospital holds") to determine whether pharmaceutical workup would be warranted and to address any issues before admission to the Home Care Program.

Throughout the pilot, the pharmacist provided staff education regularly via an electronic newsletter and in-service education at team meetings. The pharmacist attended team meetings with both service teams. The Home Care Program also invited the pharmacist to participate on its Medication Quality and Safety Committee during the pilot program.

\section{Data Collection and Analysis}

A password-protected Microsoft Access database (Microsoft, Redmond, Washington) was built to collect information about provision of pharmaceutical care. Demographic and clinical information, including age, comorbidities, allergies, and medication lists, as well as information regarding consults, drug therapy problems (DTPs) identified, recommendations made and accepted, and cpKPIs, was collected. DTPs were classified according to Hepler and Strand ${ }^{23}$; cpKPIs were classified according to the 8 categories developed by Fernandes and others. ${ }^{18}$ To maintain confidentiality, each patient was assigned a unique identifying number, and the list linking names with numbers was kept in a file separate from the database; only the unique identifying numbers were used in the database. The principal investigator (A.N.W.) performed the data analysis. Descriptive statistics are presented in aggregate.

A satisfaction survey (available from the corresponding author upon request) was developed and circulated to 72 home care staff; it was modelled on a satisfaction survey previously used by the WRHA Pharmacy Program. The survey was available online through SurveyMonkey (https://www.surveymonkey.com/); paper copies were also available. One of the nursing resource coordinators transcribed the paper responses into SurveyMonkey to ensure survey integrity. The survey was open for 14 consecutive days during April and May 2016; 1 electronic invitation and 2 electronic reminders were circulated to all 72 staff members to encourage participation. On the first day of the survey, a paper copy was also placed in each visiting nurse's mailbox, attached to the day's work assignment.

\section{RESULTS}

The pharmacist received 197 referrals involving 184 patients over the course of the pilot program. Figure 1 describes the cases included and excluded from analysis. Of the 46 exclusions involving requests to print the medication history, 37 (80.4\%) came from the case coordinators, despite the fact that these staff members had access to this information through another electronic database. Of the 11 cancelled referrals, 3 patients (27\%) refused the service, 2 patients (18\%) died or moved out of the catchment area, and 3 patients (27\%) already had service arranged with the community pharmacy; in 3 instances $(27 \%)$ the referral was not pharmacy related. Among the 138 patient intakes reviewed, 127 potential referrals were identified, of which only $2(1.6 \%)$ led to generation of a referral by a case coordinator. Of the 111 hospital holds reviewed, $2(1.8 \%)$ referrals were generated by the case coordinators.

Analysis was completed on 135 referrals for 122 individual patients (Table 1). Referrals for patients not yet receiving medication services were as numerous as for those already receiving medication administration services (50 [37.0\%] versus 49 [36.3\%] of the 135 


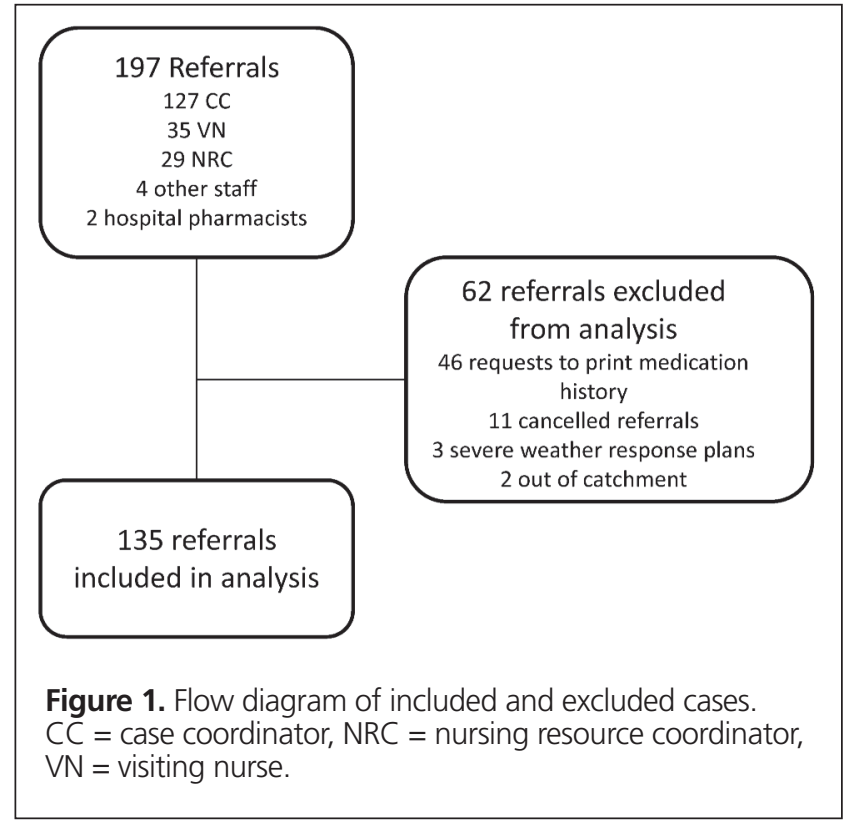

referrals). Fewer of the referred patients (36 [26.7\%]) were receiving medication assistance. Among those who received medication services, the average number of visits per day was 1.6; the breakdown of medication visits per day is described in Figure 2. The reasons for referral are shown in Table 2. The average number of reasons per referral was 1.6 (range 1-6). The pharmacist responded on the same day for 70 (51.9\%) of the 135 referrals, and the response occurred within 2 weeks (as suggested on the referral form) for an additional 51 (37.8\%) of the referrals.

Of the 135 referrals included for analysis, 40 (29.6\%) involved patients who underwent comprehensive medication review; the remainder (95 referrals [70.4\%]) involved patients who underwent targeted medication reviews or targeted educa-
Table 1. Demographic and Clinical Characteristics

\begin{tabular}{lrr} 
Characteristic & $\begin{array}{c}\text { No. (\%) of Patients* } \\
(\boldsymbol{n}=\mathbf{1 2 2})\end{array}$ \\
\hline Age (years) (mean and range) & 71 & $(12-102)$ \\
Sex, female & 77 & $(63.1)$ \\
No. of chronic conditions & 5 & $(1-9)$ \\
(mean and range) & & \\
Chronic conditions & & \\
$\quad$ Cardiovascular disorder & 96 & $(78.7)$ \\
$\quad$ Mental health disorder & 79 & $(64.8)$ \\
$\quad$ Endocrine disorder & 76 & $(62.3)$ \\
$\quad$ Musculoskeletal disorder & 72 & $(59.0)$ \\
$\quad$ Neurologic disorder & 47 & $(38.5)$ \\
$\geq 1$ drug allergy & 46 & $(37.7)$ \\
\hline *Except where indicated otherwise. & \multicolumn{3}{c}{}
\end{tabular}

tion, such as smoking cessation counselling or inhaler teaching. Most of the comprehensive medication reviews (36/40 [90\%]) were requested by case coordinators, whereas visiting nurses and nursing resource coordinators typically raised targeted questions regarding practice challenges. Twenty (14.8\%) of the referrals (involving 20 individual patients) necessitated home visits; the remainder of the medication interviews and counselling sessions were completed over the telephone.

Of the 135 referrals, 127 had one or more DTPs, with a total of 271 DTPs identified (Table 3); on average, 2.1 (range 1-6) DTPs per referral were noted. Of the 250 recommendations made by the pharmacist, most (81 [32.4\%]) were made to the prescriber; fewer recommendations were made to the case coordinator $(43[17.2 \%])$, community or acute care pharmacist (40 [16.0\%]), or patient (36 [14.4\%]). Recommendation acceptance rates are described in Figure 3. On average, 3.4 (range 1-12) encounters were required per patient to complete pharmacy involvement for each referral; these encounters included the initial

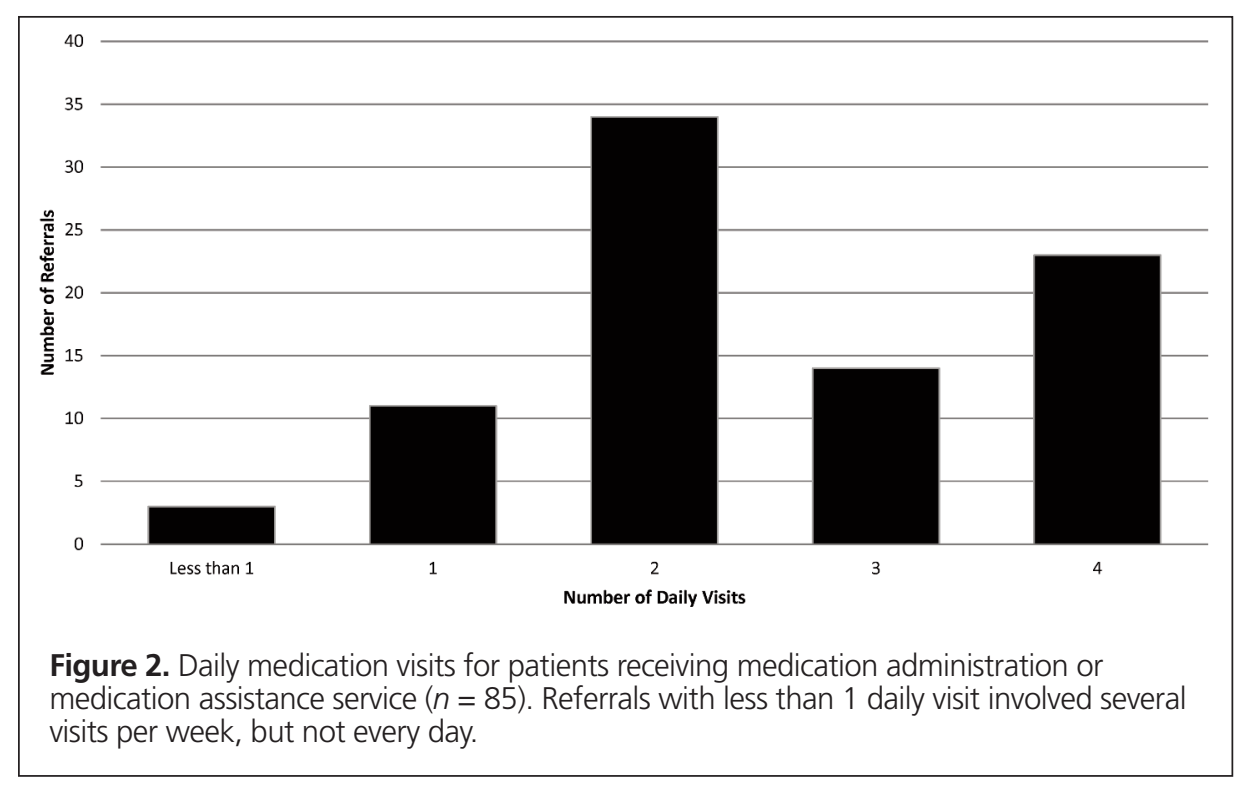


This single copy is for your personal, non-commercial use only.

For permission to reprint multiple copies or to order presentation-ready copies for distribution, contact CHHP at publications@cshp.ca

Table 2. Reason for Referral of Cases to the Home Care Pharmacist

\begin{tabular}{lrc} 
Reason for Referral & $\begin{array}{r}\text { No. (\%) of Referrals* } \\
(\boldsymbol{n}=\mathbf{1 3 5})\end{array}$ \\
\hline High-alert medications & 54 & $(40.0)$ \\
$\geq 8$ medications & 31 & $(23.0)$ \\
Poor adherence & 28 & $(20.7)$ \\
Adverse drug reaction & 20 & $(14.8)$ \\
Pain management & 19 & $(14.1)$ \\
Discharged within past 30 days & 19 & $(14.1)$ \\
Medication schedule & 9 & $(6.7)$ \\
Smoking cessation & 9 & $(6.7)$ \\
Inhaler management & 8 & $(5.9)$ \\
Difficulty taking oral medications & 6 & $(4.4)$ \\
Decreased renal function & 3 & $(2.2)$ \\
Decreased hepatic function & 3 & $(2.2)$ \\
Other & 12 & $(8.9)$ \\
*The sum of percentages is greater than 100 because some cases \\
were referred for more than one reason.
\end{tabular}

review, as well as care plan implementation and follow-up with the patient. For 4 (3.0\%) of the 135 referrals, consultation with the home care pharmacist prevented the need for home care medication services; for 8 (5.9\%) of the referrals, the pharmacist's intervention allowed the patients' service needs to be decreased; and for $4(3.0 \%)$ of the referrals, collaboration between the home care pharmacist and the acute care pharmacist resulted in changes to drug therapy that allowed for more streamlined implementation of home care service (e.g., decreasing service need before implementation of services).
Table 3. Drug Therapy Problems Identified by the Home Care Pharmacist

\begin{tabular}{lrr} 
Drug Therapy Problem & \multicolumn{3}{c}{$\begin{array}{c}\text { No. (\%) } \\
(\boldsymbol{n}=\mathbf{2 7 1})\end{array}$} \\
\hline Adherence & 102 & $(37.6)$ \\
Unnecessary drug therapy & 45 & $(16.6)$ \\
Needs additional therapy & 38 & $(14.0)$ \\
Incorrect dose & 35 & $(12.9)$ \\
Adverse drug reaction & 33 & $(12.2)$ \\
Ineffective drug & 18 & $(6.6)$ \\
\hline
\end{tabular}

A total of $180 \mathrm{cpKPIs}$ were identified in 122 of the 135 referrals; on average 1.5 (range 1-3) cpKPIs were identified per referral. The most common category of cpKPI was DTP resolution (67 [37.2\%]), followed by education (54 [30.0\%]) and development of a pharmaceutical care plan (51 [28.3\%]). Among the remaining 13 referrals, 9 instances of care did not fit within the cpKPI definitions, information was not available to assess drug therapy for 2 patients despite numerous attempts to gather it, and 2 patients were discharged from home care before completion of pharmacist care.

The survey response rate was $56.9 \%$ (41/72); nursing resource coordinators, case coordinators, and visiting nurses completed the survey most frequently (100\% [2/2], 80\% [12/15], and $62.8 \%$ [22/35], respectively); resource coordinators, team managers, and administrative assistants responded less frequently. The majority of survey respondents (39/41 [95.1\%]) had worked a minimum of 20 shifts when the home care pharmacist was

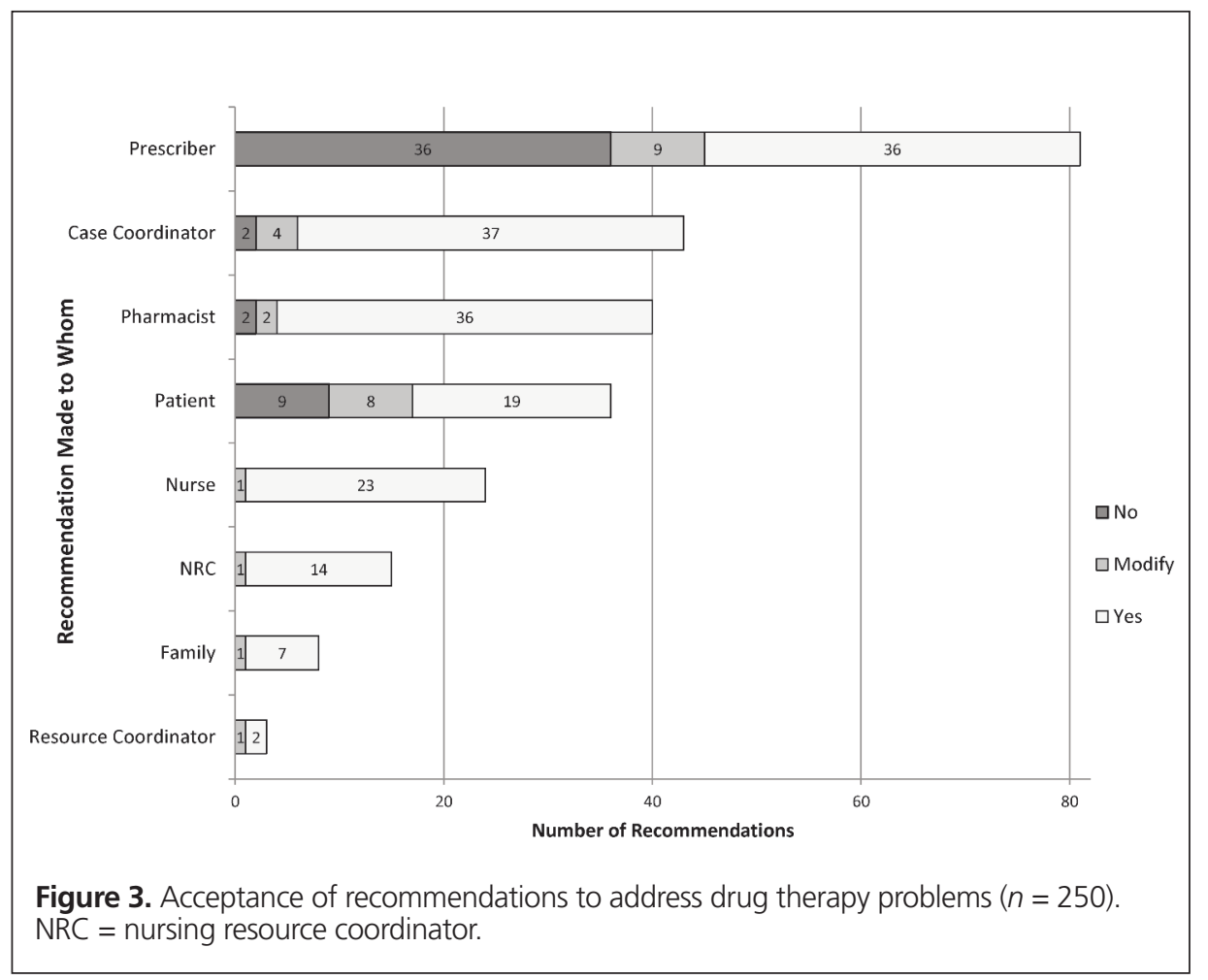


present. One-quarter of respondents (10/40 [25\%]) indicated that they had consulted the pharmacist at least once per week during the study period, and a similar number $(9 / 40[22.5 \%])$ indicated that they had not consulted the pharmacist at all. Most survey respondents agreed that the pharmacist had been accessible (35/40 [87.5\%]) and benefited the home care team (37/40 [92.5\%]). Survey respondents also agreed that home care patients benefited from the addition of pharmacist care (37/40 [92.5\%]). Said one respondent, "I have avoided long term admissions to home care through consultation with pharmacist. Support and resources provided to family and client allowed for independent and safe management of chronic health conditions without initiating daily home care service." When asked to rank the activities that the pharmacist performed, respondents ranked being available for consult, being available for drug information or other general questions, and staff education as the most valuable. Some respondents even requested more pharmacist resources: "I would think that pharmacists would need to be available $24 \mathrm{hrs}$ a day ... pharmaceutical issues can occur anytime." The pharmacist roles perceived as least valuable by survey respondents were providing feedback on home care policies and performing home visits.

\section{DISCUSSION}

The results of this pilot program have highlighted the need for enhanced pharmacy services for home care patients, as well as certain challenges related to successful implementation of the service. Almost 300 DTPs were identified in 122 patients; this finding is notable, given that the majority of these patients did not undergo a comprehensive medication review. The most commonly noted category of DTP involved challenges with adherence to drug therapy, and this was often why medication services were implemented. The most common disease state associated with non-adherence was diabetes mellitus, followed by mental health conditions. These results may mean there are opportunities for disease state-specific education to help patients with adherence to their drug therapy. There may also be further opportunities to streamline service delivery through targeted education regarding adherence aids and strategies to assist patients in becoming more independent with medication management, even if their medication regimens are complex.

The inability of the pharmacist to gather population-level data from the electronic medical records of the Home Care Program was a limitation in implementing a comprehensive pharmacy service. When starting new practices, primary care pharmacists often use case-finding strategies to identify patients for pharmacist involvement ${ }^{22,24}$; however, given the design of the Home Care Program's electronic medical records system, this approach was not feasible. Reliance on referrals, instead of seeking out at-risk patients, may have hampered the full implementation of pharmacist services: early in the pilot period, the team was less aware of the full scope of pharmacist care, indicated by the fact that $23.4 \%$ of the initial referrals were requests to print out the patient's medication history. Review of patient intakes and hospital hold files did not yield many consults either, possibly because the patient intake is a screening tool, which does not guarantee admission to the program, or because hospital hold patients may have had their drug therapy reviewed by a hospital pharmacist while still in the acute care facility. A more effective process for screening Home Care Program records as a casefinding strategy would need to be developed if the pharmacist pilot were to become a permanent element of the overall program.

Uptake and acceptance of pharmacy services was variable. Targeted reviews and education were requested more frequently than comprehensive medication reviews, which demonstrates acceptance of the pharmacist's skill and contribution to medication management, as well as some reservation about the pharmacist's ability to help manage the team's patients. Notably, case coordinators requested a more balanced percentage of comprehensive medication reviews (in relation to other types of requests), whereas nurses rarely did so; this difference may have been related to case coordinators working in the same office as the pharmacist at the start of the pilot, where they had frequent interactions with the pharmacist. The pharmacist's relationship with the nursing team was less well developed than the relationship with the case coordinators, despite the pharmacist attending the same number of meetings with nurses and case coordinators and offering the same amount of staff education to these 2 groups. Geographic proximity of the pharmacist and presence and visibility of the pharmacist on new teams have been associated with more effective team integration and team functioning. . $5,26^{2}$ The lack of sustained daily interaction with the nursing team early in the pilot program may have hindered integration of the pharmacist into nurses' work flow.

Another clear indication of team dynamics and team formation was demonstrated by the acceptance of the pharmacist's recommendations. Acceptance rates were higher (above 85\%) among home care staff and other pharmacists than among patients and prescribers (below 55\%). This clearly shows the importance of building relationships in order to implement change. Most of the patients (85.2\%) chose a phone interaction with the pharmacist, rather than a home visit, which may have affected the pharmacist's ability to fully engage with the patient and garner a complete picture of the patient's health status. Although the piloted model of care provision allowed the pharmacist to interact with more patients and respected patient autonomy, the ability to build strong patient-provider relationships was limited. Because prescribers worked external to the health authority, did not have direct interaction with the pharmacist, and did not build collaborative relationships with the pharmacist, the acceptance rate of pharmacist recommendations among prescribers was low. This rate was similar to rates seen in programs where pharmacists were not integrated into the prescriber teams ${ }^{16,27,28}$ and was much lower than rates documented 
in other settings, where the pharmacist was part of the prescriberbased team. ${ }^{6,29,30}$ If this service were to become permanent, a concentrated effort to engage prescribers from the beginning would be crucial. Trust is a significant component of functional, collaborative working relationships, but without time and repeated interactions, trust between physicians and pharmacists cannot develop..$^{26,31,32}$

Despite the above-noted challenges, Home Care Program staff who responded to the survey were supportive of the services that the pharmacist provided and recommended that the service be continued or expanded. Survey responses reflected limitations in understanding the pharmacist's role on the team; home visits were not ranked as being particularly important, but some respondents requested more of them. This may have been due to respondents' exposure to the pharmacist during home visits: those staff who had attended a home visit with the pharmacist may have valued this service more than those who had not. Staff appreciated the on-site availability of the pharmacist for patient-specific and general drug information inquires and assistance.

Of the $8 \mathrm{cpKPI}$ categories, only 3 were performed with any frequency during the pilot: resolving DTPs, pharmaceutical care planning, and direct patient education. With regard to the other cpKPI categories, medication reconciliation was performed by other team members, and interprofessional care rounds were uncommon. Discharge medication counselling was rarely needed, because when patients are discharged from the Home Care Program it is often to an environment where medication selfmanagement is not needed (e.g., long-term care facility). Finally, because of the lack of solidified collaborative relationships, proactive pharmaceutical care was challenging and most service was reactive. Proactive strategies that were used during this pilot program did not translate into referrals for the pharmacist, contrary to the success that has been described in primary care pharmacy. ${ }^{22,24}$ While some pharmacist activities can be classified using the acute care cPKPI measures, it may be of more value to identify specific cpKPIs for ambulatory care. For example, pharmaceutical care planning could be further distilled into chronic disease management, acute issue resolution, drug procurement, and other aspects of care. Admission and discharge qualifiers may not be necessary for ambulatory care cpKPIs, as patients and providers may not consider a return from hospital as an "admission" to primary care. Pharmacy performance indicators for ambulatory care represent an area for further research.

\section{CONCLUSION}

The addition of a clinical pharmacist to the Downtown Community Area Home Care Program team demonstrated a need for enhanced access to clinical pharmacy services for home care patients; however, the best service model remains unclear. A future study could compare home care-based pharmacists with primary care-based pharmacists to determine which type of provider is better positioned to optimize pharmacotherapy for home care patients. More research is warranted to determine the optimal pharmacy service for home care patients and the most appropriate cpKPIs to measure its effect.

\section{References}

1. Romanow RJ. Building on values: the future of health care in Canada-final report. Saskatoon (SK): Commission on the Future of Health Care in Canada; 2002.

2. Home and community care. Ottawa (ON): Government of Canada; 2016 [cited 2016 Nov 5]. Available from: http://healthycanadians.gc.ca/ health-system-systeme-sante/services/home-domicile/commuitycommunautaires-eng.php

3. Doran DM, Blais R. Safety at home: a pan-Canadian home care safety study. Edmonton (AB): Canadian Patient Safety Institute; 2013.

4. Aggregate analysis of medication incidents in home care. ISMP Can SafBull. 2014;14(8):1-7.

5. Riker GI, Setter SM. Polypharmacy in older adults at home: what it is and what to do about it-implications for home healthcare and hospice, part 2. Home Healthc Nurse. 2013;31(2):65-77.

6. MacAulay S, Saulnier L, Gould O. Provision of clinical pharmacy services in the home to patients recently discharged from hospital: a pilot project. Can J Hosp Pharm. 2008;61(2):103-13.

7. Flanagan P, Virani A, Baker W, Roelants H. Pharmacists making house calls: innovative role or overkill? Can J Hosp Pharm. 2010;63(6):412-9.

8. MacKeigan LD, Nissen LM. Clinical pharmacy services in the home. Dis Manag Health Outcomes. 2008;16(4):227-44.

9. Reidt SL, Larson TA, Hadsall RS, Uden DL, Blade MA, Branstad R. Integrating a pharmacist into a home healthcare agency care model: impact on hospitalizations and emergency visits. Home Healthc Nurse. 2014; 32(3):146-52.

10. Bond CA, Raehl CL. Clinical pharmacy services, pharmacy staffing, and hospital mortality rates. Pharmacotherapy. 2007;27(4):481-93.

11. Kaboli PJ, Hoth AB, McClimon BJ, Schnipper JL. Clinical pharmacists and inpatient medical care: a systematic review. Arch Intern Med. 2006; 166(9):955-64.

12. Gillespie U, Alassaad A, Henrohn D, Garmo H, Hammarlund-Udenaes M, Toss $\mathrm{H}$, et al. A comprehensive pharmacist intervention to reduce morbidity in patients 80 years or older: a randomized controlled trial. Arch Intern Med. 2009;169(9):894-900.

13. Furbish SML, Kroehl ME, Loeb DF, Lam HM, Lewis CL, Nelson J, et al. A pharmacist-physician collaboration to optimize benzodiazepine use for anxiety and sleep symptom control in primary care. J Pharm Pract. 2017; 30(4):425-33.

14. Santschi V, Chiolero A, Burnand B, Colosimo AL, Paradis G. Impact of pharmacist care in the management of cardiovascular disease risk factors: a systematic review and meta-analysis of randomized trials. Arch Intern Med. 2011;171(16):1441-53.

15. Lee JK, Grace KA, Taylor AJ. Effect of a pharmacy care program on medication adherence and persistence, blood pressure, and low-density lipoprotein cholesterol: a randomized controlled trial. JAMA. 2006;296(21):2563-71.

16. Reidt S, Morgan J, Larson T, Blade MA. The role of a pharmacist on the home care team: a collaborative model between a college of pharmacy and a visiting nurse agency. Home Healthc Nurse. 2013;31(2):80-7.

17. Zillich AJ, Snyder ME, Frail CK, Lewis JL, Deshotels D, Dunham P, et al. A randomized, controlled pragmatic trial of telephonic medication therapy management to reduce hospitalization in home health patients. Health Serv Res. 2014;49(5):1537-54.

18. Fernandes O, Gorman SK, Slavik RS, Semchuk WM, Shalansky S, Bussières JF, et al. Development of clinical pharmacy key performance indicators for hospital pharmacists using a modified Delphi approach. Ann Pharmacother. 2015;49(6):656-69.

19. Armstrong B. Celebrating 40 years of home care. Wave: Winnipeg's Health o Wellness Magazine. 2014;6(5):38.

20. WRHA Home Care Program. Medication assistance with oral medications by direct service staff. Winnipeg (MB): Winnipeg Regional Health Authority; 2013. 
21. WRHA Home Care Program. Section 3.4: Medication administration guidelines. In: Nursing procedures manual. Winnipeg (MB): Winnipeg Regional Health Authority; 2015.

22. Jorgenson D, Dalton D, Farrell B, Tsuyuki RT, Dolovich L. Guidelines for pharmacists integrating into primary care teams. Can Pharm J. 2013; 146(6):342-52.

23. Hepler CD, Strand LM. Opportunities and responsibilities in pharmaceutical care. Am J Hosp Pharm. 1990;47(3):533-43.

24. Barry AR, Pammett RT. Applying the guidelines for pharmacists integrating into primary care teams. Can Pharm J. 2016;149(4):219-25.

25. Jenkins AI, Hughes ML, Mantzourani E, Smith MW. Too far away to work with each other: does location impact on pharmacists' perceptions of interprofessional interactions? J Interprof Care. 2016;30(5):678-81.

26. Jorgenson D, Laubscher T, Lyons B, Palmer R. Integrating pharmacists into primary care teams: barriers and facilitators. Int J Pharm Pract. 2014; 22(4): 292-9.

27. Sellors J, Kaczorowski J, Sellors C, Dolovich L, Woodward C, Willan A, et al. A randomized controlled trial of a pharmacist consultation program for family physicians and their elderly patients. CMAJ. 2003;169(1):17-22.

28. Bryant LJM, Coster G, Gamble GD, McCormick RN. The General Practitioner-Pharmacist Collaboration (GPPC) study: a randomised controlled trial of clinical medication reviews in community pharmacy. Int J Pharm Pract. 2011;19(2):94-105.

29. Campins L, Serra-Prat M, Gózalo I, López D, Palomera E, Agusti C, et al.; REMEI Group. Randomized controlled trial of an intervention to improve drug appropriateness in community-dwelling polymedicated elderly people. Fam Pract. 2017;34(1):36-42.

30. Von Muenster SJ, Carter BL, Weber CA, Ernst ME, Milchak JL, Steffensmeier JJG, et al. Description of pharmacist interventions during physician-pharmacist co-management of hypertension. Pharm World Sci. 2008;30(1):128-35.

31. Gregory PAM, Austin Z. Trust in interprofessional collaboration: perspectives of pharmacists and physicians. Can Pharm J. 2016;149(4):236-45.
32. Bradley F, Elvey R, Ashcroft DM, Hassell K, Kendall J, Sibbald B, et al. The challenge of integrating community pharmacists into the primary health care team: a case study of local pharmaceutical services (LPS) pilots and interprofessional collaboration. J Interprof Care. 2008;22(4):387-98.

Ashley N Walus, BScPharm, ACPR, is a Clinical Resource Pharmacist Educational Services with the Winnipeg Regional Health Authority Pharmacy Program, Winnipeg, Manitoba.

Donna M M Woloschuk, BSP, PharmD, MEd(Distance), FCSHP, was, at the time of this project, the Regional Pharmacy Manager - Educational Services, Winnipeg Regional Health Authority, Winnipeg, Manitoba. She is now a Pharmacy Consultant in Calgary, Alberta.

Competing interests: None declared.

\section{Address correspondence to:}

Ashley N Walus

WRHA Pharmacy Program

N245, North Pavilion, Deer Lodge Centre

2109 Portage Avenue

Winnipeg MB R3J OL3

e-mail: awalus@wrha.mb.ca

Funding: This work was funded by the Winnipeg Regional Health Authority.

Acknowledgements: The authors would like to thank Edith Kovacs and the WRHA Downtown Community Area Home Care team for their enthusiastic participation in this pilot program. Thanks are also extended to Brendon Mitchell for his assistance with manuscript preparation. 